\title{
Nurse practitioner student preceptor orientation via a Wiki
}

\author{
Cathy Koetting *' Kris L’Ecuyer, Margaret Benz \\ School of Nursing, Saint Louis University, St. Louis, United States
}

Received: September 19, 2014

Accepted: November 25, 2014 Online Published: December 16, 2014

DOI: $10.5430 /$ jnep.v5n2p124

URL: http://dx.doi.org/10.5430/jnep.v5n2p124

\begin{abstract}
Nurse practitioner education programs have always partnered with nurse practitioners (NPs) to serve as preceptors for students completing clinical requirements of their graduate level nurse practitioner programs. In this model faculty rely on nurse practitioners for the clinical education of nurse practitioner students. Therefore, the preceptor role is a crucial element of NP education particularly in distance learning programs. Orientation to the role is essential to ensure educational competencies are achieved. Nursing faculty struggle with implementation of orientation that is efficient and meets the needs of all preceptors for all clinical courses. Orientation requirements to the nurse practitioners' role as preceptor can be a barrier to acquiring and retaining preceptors. The purpose of this study was to acquire information from NP preceptors regarding willingness to participate in a NP preceptor orientation program, the type of information they desired in a NP preceptor orientation, and the preferred delivery system for this information. Former preceptors from our school of nursing's database were sent an online survey with 15 questions regarding orientation for NP preceptors. Descriptive statistics were used to summarize preceptor needs and preceptor barriers. Qualitative findings from written comments found many preceptors perceive school of nursing faculty organizational support is vital in terms of how positively they view their role as a preceptor and their willingness to participate in an orientation program. The results of the survey were used to re-design nurse practitioner preceptor orientation in our school of nursing. The WIKI online method was chosen due to its ease of information dissemination, which met the administrative needs of faculty; and its convenience and availability, which met the accessibility needs of preceptors.
\end{abstract}

Key Words: Preceptor, Nurse practitioner students, Nursing faculty, Orientation, Organizational support

\section{Introduction}

Nurse practitioner programs are required to orient NP preceptors to their role, ${ }^{[1]}$ and to the particular needs of the student in clinical courses. Traditionally, the student delivers written information to the preceptors. As a result of this method, vital preceptor information may not always successfully get to the preceptor. If the material is received by the preceptor, is it unknown whether the quality and applicability of the information is appropriate to meet the education needs of the NP preceptor. ${ }^{[2]}$ Since NP programs are held accountable, it is important that NP faculty know if the material is meeting the goal of educating the preceptor and that no barriers exist for the preceptor to easily obtain the information. The study builds on other studies discussing preceptor motivation, perceived organizational support and educational preparation of NP preceptors ${ }^{[3-6]}$ particularly in areas of faculty contact and motivation to be a preceptor. This study adds to nursing knowledge by providing NP perspective regarding specific information desired in a preceptor orientation, and insight into preceptor motivation and needs for faculty support. States. 
In our institution, a faculty goal was to develop a specific and tangible orientation for preceptors of NP students that could be easily accessed and easily updated. Faculty also wanted a specific orientation program for student NP preceptors that met the National Organization of Nurse Practitioner Faculties (NONPF) requirements particularly in light of upcoming CCNE evaluation. The idea of a preceptor orientation by use of a wiki was one platform that would meet all goals.

Study objectives were: 1) to determine the learning needs of NP preceptors that could be used to develop a preceptor orientation curriculum; 2) to identify an efficient methodology to orient NP preceptors which would meet the needs of the preceptor, the student, the faculty, and the university; and 3 ) to fulfill the requirements of the certifying organizations. Survey questions included querying preceptors about their thoughts on preceptor orientation and their relationship with course faculty. These results showed that many preceptors viewed a formal preceptor orientation as a barrier to becoming a preceptor. Preceptors also discussed certain barriers to the preceptor role, such as time commitment, lack of motivational incentives (particularly monetary), faculty status concerns, lack of communication, and perceived organizational support from the nursing faculty who taught the clinical courses. While several of these themes have been explored in nursing research, our study was unique in that it also provided evidence that supported the implementation of an up to date, online, easy to access orientation methodology.

\section{Relevant scholarship/literature}

A mentor is an influential person who helps protégés reach their life goals by providing informational resources and being a professional role model. Nursing literature often uses the terms mentor and preceptor interchangeably. The role of the preceptor is the focus in nurse practitioner education. A preceptor promotes professional and personal development as a part of the process in which the student engages, along with assisting the transition to advanced practice. ${ }^{[7]}$ While mentoring refers to a new graduate's socialization to the NP role, the NP preceptor is the person who helps shape and educate the student to a role they need to embrace by graduation. Hence, NP preceptors' role contains unique challenges because it demands a balance between daily teaching of clinical practice and clinical practice expectations. ${ }^{[8]}$ This dichotomy is reflected when evaluating issues involved with NP preceptors and the need for a harmonious and synchronous structure for NP student clinical education. It also elucidates various issues and barriers found in the relevant literature.

Law and colleagues ${ }^{[9]}$ performed a literature search regarding the support and retention of nurse practitioner preceptors. Four major themes emerged: 1) professional organization standards; 2) preceptor role and successful preceptor

Published by Sciedu Press characteristics; 3) preceptor role barriers and facilitators; and 4) support and retention of preceptors. Other authors have also discussed these four themes. NONPF considers the preceptor role to be the foundation of clinical education. It is imperative that NP preceptors be supported by NP faculty in order to be valued members of the students' entire learning experience. NP preceptors gain benefits by being a preceptor, particularly through establishing a relationship with a university, and the opportunity to help shape the future of healthcare. ${ }^{[10]}$ A survey conducted by NONPF of over 600 preceptors was used to analyze the workload of NP preceptors. Results showed on average preceptors worked two additional hours for each day they acted as NP preceptor along with performing their regular NP duties. ${ }^{[11]}$ The NONPF survey identifies the issue that being a preceptor can result in a large time investment in the role and even lost wages. It is very important for preceptors to not only be self-motivated and have support, but support must be tangible and non-tangible in nature.

Marfell ${ }^{[11]}$ defines the interaction of preceptor and student as an association between a novice learner and an experienced learner in the same specialty. This is a voluntary connection. She notes that the most successful of these relationships is made when the preceptor has a vested interest in the student's learning experience, and has a high degree of altruism. There is not a specific incentive for the preceptor with the exception of developing a new NP colleague; a professional expectation. Besides the student and the preceptor, university faculty who teach in clinical courses are also involved in this relationship. The faculty represents the organizational support needed by both preceptor and student. Faculty have a role in this relationship as facilitators, and should guide the student and preceptor to help establish mutual learning goals, and help plan the methodology for goal achievement. Faculty should communicate with preceptors regarding student performance and educational needs. It is important to note that this type of dialogue can begin in a preceptor orientation program.

Brook and Niederhauser ${ }^{[12]}$ used an open-ended question and Likert scale survey to answer the questions of NP preceptor expectations of university faculty members and students, understand top communication interventions between faculty and NP preceptors, and to discover what areas of improvement were needed to ensure optimum preceptor experiences. The cross-sectional descriptive study used a single one-time survey with a convenience sample of preceptors from the researchers' university. Results showed preceptors felt that the focus of the faculty visit was to assess the skill level of the NP student and to evaluate the appropriateness of the site to the course goals. Over $50 \%$ of the preceptors also emphasized the need for private communication with the faculty regarding the student's performance and areas of improvement. ${ }^{[12]}$

Nurse practitioner program curriculums are designed to pro- 
duce particular outcomes. These outcomes are described as the Masters Essentials; a set of competencies that must be mastered by program termination. ${ }^{[13]}$ As NP preceptors must teach and practice clinically in one setting, there is a great need to know what to focus on during the clinical preceptorship. Besides the syllabus and other materials that the student brings to the clinical site, the preceptor must also be familiar with the Masters Essentials to help the student meet these desired outcomes. ${ }^{[13]}$ Many NP preceptors struggle with this daunting task. NP preceptors also are unable to always know how much skill and competence the student brings to the clinical setting. One solution to this dilemma is to use a capability framework instead of a competency based one. ${ }^{[14]}$ This type of framework serves to help NP preceptors develop a clinical teaching situation where the student is educated to cope with the unknown and be versatile and accommodating to the individual patient situation. A capable NP graduate can take those problems and contexts in the workplace that are familiar and apply them to unfamiliar contexts. By relying on their ability to create and devise solutions in unfamiliar settings, capable NP graduates trust their intuition, acumen, and diagnostic skills thereby using acquired knowledge and skills in advanced ways. ${ }^{[14]}$

While NP preceptors must be self-efficacious, they must also receive some type of rewards for their efforts. Hetzel and colleagues ${ }^{[15]}$ surveyed 26 faculty members coordinating and teaching clinical courses that included a preceptor site with a NP preceptor. Administered via personal contact and email, the purpose was to uncover how faculty nurture and reward clinical preceptors and what type of supports preceptors needed. The researchers used the 2005 NONPF conference attendance list as the database to contact the potential participants. The sample was varied and represented a range of institutions offering a NP program. Of the 26 participants, only 1 represented a nursing school that did not offer any type of reward to the NP student preceptors. Rewards included tuition and continuing education vouchers, verification of hours toward recertification, and a discount on conference registration at schools sponsoring a conference. Access to services such as library privileges, borrowing software, museum admission, and reduced admission to university events were also given in gratitude for preceptor participation. ${ }^{[15]}$ The data from this survey suggest NP faculty across the US have become more resourceful regarding rewarding NP preceptors. It also supports the concept rewards can be a motivating factor to recruit and retain NP preceptors.

In order to retain preceptors, schools of nursing must be cognizant of factors related to a preceptor's willingness and ease of being a preceptor in his/her unique clinical environment. Lyon and Peach ${ }^{[5]}$ performed a qualitative study to understand the components that facilitated or inhibited NP willingness to become a preceptor. The researchers used a purposive, convenience sample from a preceptor database from a Mid Atlantic university. A semi-structured phone interview was conducted with 24 NP preceptors whose answers were taped and transcribed. The responses were organized into thematic categories using constant comparative methods of qualitative analysis. ${ }^{[5]}$ Results were similar to other studies. ${ }^{[9]}$ Several NPs stated they felt a responsibility to pay back their profession. Others stated they felt that there was a lack of NP role models for new NPs to emulate. Preceptors also noted that communication between preceptors and faculty was vital in order to understand preceptor requirements in a particular clinical course. Site visits were also mentioned as necessary for successful communication with the school of nursing. Preceptors were specific in their comments about student skill level. While many enjoyed taking beginning students, others were vocal about making sure students had some basic skills in that area of practice before they entered the clinic. Pelvic exams were mentioned as one example of a skill that should not be taught in the clinical setting. Lastly, preceptors discussed practice related barriers. These barriers included primary care practice with high patient volume, liability concerns, and physical space limitations, decreased billing ability, and even restricted access by third parties such as health maintenance organizations. ${ }^{[5]}$

Two other facets of being a NP preceptor are important to include: the clinical teaching of collaboration with other members of the interdisciplinary team and the role of spirituality in patient care and management. Issues such as medication adherence are common problems in the primary care setting. Reaching out to other members of the healthcare team, such as the pharmacist can help patients reach appropriate outcomes when dealing with multiple medications. ${ }^{[16]}$ A collaborative practice project was implemented by Family Nurse Practitioners (FNPs) at a primary care clinic. Their sample consisted of patients who were identified by the FNPs as being on a multi-drug regimen and diagnosed with uncontrolled diabetes mellitus type 2 . Once identified these patients were referred to the pharmacist for face to face counseling in which the pharmacist reviewed the medication list, answered patient's questions, and then queried patients about time of day dosing, the possibility of combination medication use and cost. A follow up visit with the FNP reviewed the medication regimen suggested by the pharmacist, addressed questions, and medication regiments changed as needed. Follow up with the FNP and the pharmacist was also available to the patient for the 6 month time period. Hemoglobin A1c levels were measured at the beginning and at the end of the 6 month intervention period. The researchers found a mean change in the A1c level of 0.99 and this was found to be significant. Not only does this research show a productive and successful collaboration to the problems faced by medication adherence, it offers an opportunity to show the use of evidence based practice for NP students. ${ }^{[16]}$ 
Lastly, educating NP students to address spirituality as a part of patient management is very challenging and can be an important aspect to NP preceptor education. NONPF discusses spiritual care is a part of NP practice and identified spiritual competencies required for NPs. ${ }^{[17]}$ Integrating this knowledge into the clinical practicum can be taxing for NP preceptors. In all, NP preceptors take on immense responsibility, must juggle this responsibility with the responsibilities of their own clinical practice, and may do so with little faculty collaboration or reward. There are several barriers for schools of nursing to address when collaborating with their clinical preceptor colleagues.

\section{Methods}

\subsection{Participants}

The participants for this study were a convenience sample drawn from a preceptor database maintained by the school of nursing for the years 2005-2013. The preceptor database is a listing of all preceptors used by advanced practice nurse practitioner students in clinical settings during the aforementioned time frame. The preceptors in the database are both male and female. The participants were at least 21 years of age by virtue of their education backgrounds and work status. The database at the school of nursing includes only nurse practitioners, physicians, both MD and DO and physician assistants who work in hospital-based, clinic-based or primary care based specialty areas. The researchers selected preceptors from the years 2009-2013 to ensure they easily recalled their experience as a preceptor. The identified group consisted of 1469 preceptors $(n=1469)$ with non- duplicated emails. Inclusion criteria for receiving a survey were only that the participant was a former NP preceptor from the years $2009-2013$.

\subsection{Materials}

The survey tool was a 15-item questionnaire, of which 11 were multiple choice, two were rank-ordered, and two were short answer. All responses were anonymous as the IP address was blocked. The survey was created with use of Qualtrics, an online survey software that can be set to automatically block the IP address, eliminating any identification of the survey participant. Demographic data such as age, gender, type of degree (physician, advanced practice nurse, or physician assistant), address, and work setting were not included in the survey because the researchers believed this data did not contribute to the purpose of the study.

\subsection{Procedure}

A descriptive, cross sectional design was used for this study. Following Institutional Review Board approval, the sample of 1469 preceptors was sent an email with a link that allowed access to the survey. This initial email was a cover letter that explained the purpose of the "Preceptor Orientation Survey". The purpose was to seek former preceptor input into the development of a preceptor program to assist current and future preceptors in their work with our university nurse practitioner students. The two research questions the investigators sought to answer were: 1- what types of material would benefit preceptors in a preceptor orientation program? And 2- what delivery methodology do NP preceptors prefer in a NP orientation?

\section{Results}

While 1469 former preceptors were sent an email asking them to participate in the survey, 276 agreed to complete the survey. While most participants answered all 15 questions, a small number of surveys were incomplete. Incomplete surveys were included in data analysis. Overall there was an $18.7 \%$ return rate. Demographical information showed that most respondents had recently become NP student preceptors. When asked length of time the NP had been a preceptor for Saint Louis University, over half the respondents reported they had been preceptors for less than three semesters showing that the sample was fairly new to the preceptor role. While an overwhelming majority of the sample stated they reviewed the preceptor packet of materials provided by the student and responded it helped them define their responsibility in their preceptor role, $66 \%$ of these respondents stated they would not find an orientation helpful to better understand their role as a preceptor. When asked about the importance of a preceptor orientation to prepare them for their preceptor role for a NP student, $29 \%$ felt it was somewhat important and $24 \%$ felt that it was neither important nor unimportant. Fifteen percent of the respondents felt that the preceptor orientation was very or extremely important, and $32 \%$ responded that an orientation was either not all important, or very or somewhat unimportant. These statistics show that preceptors are not only divided about what preparation is needed for their preceptor role, but also that they are incongruent regarding types of organizational support, such as a preceptor orientation, needed to enact their role.

The top three most preferred methods of delivery of a preceptor orientation were informational documents sent by email attachments (37\%), paper packet delivered by mail $(21 \%)$, and a link to a WIKI website where I can view and download the information I need (18\%). Preceptors were asked to rank the preferred items to include in a preceptor orientation. The top three items desired were information regarding what the student expects from the preceptor $(40 \%)$, information regarding what the preceptor should expect from the student (30\%), and how to evaluate the student $(15 \%)$.

Regarding the faculty role of establishing communication with the preceptor, $82 \%$ reported they knew how to contact our School of Nursing faculty if needed, while $20 \%$ felt 
they did not. Of this same sample, $69 \%$ stated that they have never contacted a school of nursing faculty member, and $24 \%$ stated that they have rarely contacted a school of nursing faculty member. Only $14 \%$ stated they sometimes contacted a faculty member and only three percent of the respondents in the sample stated that they frequently contacted faculty members. Hence, while a large majority reported they knew how to contact the faculty, a very small amount did contact faculty. The survey was not designed to delve further into this issue; however it would be helpful to better understand preceptors' perceptions regarding communication with faculty. Preceptors were asked to recall the typical reason they have contacted a faculty member in the past. This question related directly to the known literature regarding preceptor's perceived organizational support. The majority of written comments focused on the need to provide some type of feedback to the course faculty. Rating the satisfaction level with faculty contact and support, $47 \%$ of the sample was neutral about their satisfaction with faculty contact and support. And while a total of $7 \%$ were very dissatisfied, dissatisfied or somewhat dissatisfied with faculty contact and support, $46 \%$ were either satisfied or very satisfied with the faculty contact and support they received as a preceptor for our program. Preceptors were also queried regarding previous participation in a preceptor orientation from another university. Results showed 68\% had no previous participation in a preceptor orientation program while $32 \%$ did have precious participation. Respondents were encouraged to provide written comments regarding this type of participation experience.

Two questions discussed clinical rotation expectations in the clinical setting and the information packet for preceptors. Eighty two percent of the respondents replied expectations for clinical rotations for each student precepted were clear and $83 \%$ stated that the information packet was helpful. The rest of the survey elicited verbal comments as a follow up to the questions about an NP preceptor orientation and other general ideas or thoughts. These comments centered on the themes of barriers to precepting, communication needs between institutional faculty and preceptors, desire for specific information regarding clinical skills to be taught and learned in the clinical site, desire to engage in a preceptor orientation and overall perceived institutional support. These modules focus on the needs of the preceptor so that they begin to understand what is expected of them and to feel supported by the NP faculty.

\section{Discussion}

Our results showed that most participants preferred to obtain the orientation materials as an email attachment. While the WIKI method was the third top choice at $18 \%$, it was also apparent through the anecdotal comments that access to an orientation site should be easy and quick, not require a special password, and be accessible 24 hours a day. Based on those desired traits, and in consideration of administrative constraints, we felt the online WIKI methodology was the best option to deliver our preceptor orientation.

The WIKI site was set up on the public domain: wikispaces.com. In the past WIKIs were designed to allow public access for individuals to collaboratively allow editing of a website. In this case, the ease of collaborative editing of content would aid the NP program at the school of nursing. Because the plan was to have one WIKI for all clinical courses, as the courses changed each semester, so could the accompanying WIKI content. Preceptors were given letters by the NP student that introduced the school of nursing and the WIKI. The letter contained the wiki site link: https://slupreceptornp. wikispaces. com/SLU+NP+Preceptor+Home+Page. Once the preceptor pasted the link into a web browser, that preceptor immediately was given access to the WIKI NP preceptor site home page. The home page lays out the entire site for the user. The first link, Getting Started, contains Module One composed of an introduction to the school of nursing via three short videos. Once the Module One link is accessed, users may continue through the various modules which are designed to provide information about preceptor role, assessment of learning needs and building a relationship, preceptor evaluation in the clinical setting, and general clinical preceptor trouble shooting.

In addition to the Getting Started link, there is also a link called Toolbox. This link contains the university and school of nursing mission statements, school of nursing philosophy, progression of the NP student in the curriculum, position description of the preceptor and two articles discussing the preceptor role. The last sets of links on the home page are the course numbers and course names for all the clinical courses at the school of nursing in the NP program. They begin with the Health Assessment course link then continue through in chronological sequence by NP track: Acute care Adult Gerontological nurse practitioner, Adult Gerontological primary care nurse practitioner, Family nurse practitioner, Pediatric nurse practitioner, and Psych Mental Health nurse practitioner. Down the left side of the Home page is a navigation pane that mirrors the links on the Home page. Hence, users can access the entire site by clicking on the links they wish to view. This allows for personal choice of the preceptor user regarding how much or how little of the orientation program and course information they wish to access. For those preceptors who access the entire five modules, a continuing education credit of 2.0 credit hours is awarded through registration, evaluation and short post orientation quiz.

The five orientation modules were designed to address those issues and barriers identified by the literature that correlated with anecdotal comments of our sample in the survey. The first module gives the user a real world identity to our university. Professionally recorded videos visually take the 
user through the campus focusing on the schools of Health Science and Nursing at the university. Because perceived organizational support is such an integral aspect of successful preceptor relationships, we wanted to address this issue identified by our sample in the survey. ${ }^{[3]}$ The videos show that the school of nursing is housed in a top ranked healthcare institution that is active in research where duty is defined as "cura personalis", or care for the entire person. ${ }^{[18]}$ Since we are a Jesuit university, we also felt that highlighting our ideology and Jesuit Mission was important for us to communicate to our preceptors. These videos aid this perceived organizational support.

The second module is focused on the preceptor role. ${ }^{[4,5]}$ Here preceptors are given a brief, yet succinct power point on preceptor role, responsibilities, the coaching role and how to nurture this role. Module three consists of information regarding types of learning styles, characteristics of adult learners, passive training and active training styles to use as a preceptor, moving the student along the learning continuum, and what actions are indicative of an effective preceptor. Module four helps the preceptor to use evaluation tools in the clinical setting by taking the preceptor through the steps of our evaluation tool. Module five focuses on trouble shooting uses that can arise in the clinical setting between preceptor and student: conflict resolution, constructive criticism, red flags, and modeling critical thinking.

\section{Conclusions}

This current study provided both statistical and anecdotal information that showed preceptors may find a formal orientation a barrier to becoming a preceptor. Important issues that the school of nursing discovered centered on preceptors' perceived organizational support, ease and accessibility of a preceptor orientation, and the desire for more information on expectations of student and preceptor in each clinical course. The orientation site created by our school of nursing using the WIKI methodology allows for ease of access, can be edited quickly as courses are updated or scheduled each semester, and provides ample information for support of the preceptor through information on role, evaluation, and building a preceptor relationship. The site also allows for preceptors to obtain continuing education credit for its free use, thus rewarding preceptor time and efforts. The WIKI for NP orientation is the unique in format and methodology. It meets all the requirements of NONPF for orienting NP preceptors, and it allows preceptors to individualize their orientation based on their experience, time constraints, and education needs.

\section{Conflicts of Interest Disclosure}

The author declares that there is no conflict of interest statement.

\section{References}

[1] National Organization of Nurse Practitioner Faculties National Task Force on Quality Nurse Practitioner Education. Criteria for evaluation of nurse practitioner programs. Washington, DC. National Organization of Nurse Practitioner Faculties. 2012.

[2] Barker, E. Becoming a super preceptor: A practical guide to preceptorship in today's clinical climate. Journal of the American Academy of Nurse Practitioners. 2010; 22: 144-149. PMID:20236398 http: //dx.doi.org/10.1111/j.1745-7599.2009.00487.x

[3] Wiseman, R.F. Suvey of Advanced Practice Student Clinical Preceptors. Journal of Nursing Education. 2013; 52(5): 253258. PMID:23495701 http://dx.doi.org/10.3928/0148483 4-20130319-03

[4] Henderson, A, Fox, R, Malko-Nyhan,K. An evaluation of preceptors' perceptions of educational preparation and organizational support for their role. Journal of Continuing Education in Nursing. 2006; 37(3): 130-136. PMID:18814394

[5] Lyon, DE, Peach, J. Primary care providers' views of precepting nurse practitioner students. Journal of the American Academy of Nurse Practitioners. 2001; 13(5): 237-240. PMID:11930475 http: //dx.doi.org/10.1111/j.1745-7599.2001.tb00027.x

[6] Armella, EJ, Brown,L, Resnick, B, Behler McArthur, D. Partners for NP Education: The 1999 Preceptor and Faculty Survey. Journal of the American Academy of Nurse Practitioners. 2001; 13(11): 517-523. http://dx.doi.org/10.1111/j.1745-759 9.2001.tb00018.x

[7] Meier, SR. Concept analysis of mentoring. Advances in Neonatal Care. 2013; 13(5): 341-345. PMID:24042140 http://dx.doi.o $\mathrm{rg} / 10.1097 / \mathrm{ANC} .0 \mathrm{~b} 013 \mathrm{e} 3182 \mathrm{a} 14 \mathrm{ca} 4$
[8] Payne, C, Heye, ML, Farrell, K. Securing preceptors for advanced practice students. Journal of Nursing Education and Practice, 2014; 4 (3): 167-179.

[9] Law Wilson, L, Bodin, MB, Joffman, J, Vincent, J. Supporting and retaining preceptors for NNP Programs: Results from a survey of NNP preceptors and program directors. Journal of Perinatal and Neonatal Nursing. 2009; 23(3): 284-292. PMID:19704299 http://dx.doi.org/10.1097/JPN . 0b013e3181b3075d

[10] Johnston, C, Mohide,EA. Addressing diversity in clinical nursing education: support for preceptors. Nursing Education Practice. 2009; 9: 340-347. PMID:18838304 http://dx.doi .org/10.10 $16 / j$.nepr.2008.08.005

[11] Marfell, J. Preceptors-the cornerstone of clinical education. The Nurse Practitioner. 2011; 36(6): 6-7. PMID:21572291 http://dx .doi.org/10.1097/01.NPR.0000397918.13316.f7

[12] Brooks, MV, Niederhauser, VP. Preceptor expectations and issues with nurse practitioner clinical rotations. Journal of the American Academy of Nurse Practitioners. 2010; 22: 573579. PMID:21054630 http://dx.doi.org/10.1111/j.1745-7 $599.2010 .00560 . x$

[13] American Association of Colleges of Nursing, The Essentials of Masters's Education for Advanced Practice Nursing. 1996. Available from: http: www.aacn.nche.edu/education-resources /MasEssentials96.pdf

[14] O'Connell, JO, Gardner, G, Coyer, F. Beyond competencies: using a capability framework in developing practice standards for advanced practice nursing. The Journal of Advanced Nursing. 2014; 27282735. PMID:25109608 http://dx.doi.org/10.1111/jan. 124 75

[15] Hetzel Campbell, S, Hawkins, JW. Preceptor rewards: how to say thank you for mentoring the next generation of nurse practitioners. 
Journal of the American Association of Nurse Practitioners. 2007; 19 (1): 24-29. PMID:17214864 http://dx.doi.org/10.1111/j $.1745-7599.2006 .00186 . x$

[16] Diggins, K. Family Nurse Practitioner/Pharmacist Collaborative Medication Counseling in Patients with Diabetes. The Journal for Nurse Practitioners. 2014; 10(9): 741-744. http://dx.doi.org $/ 10.1016 / j$. nurpra.2014.05.011
[17] Haley, J. Classroom to Clinic: Incorporating Adolescent Spiritual Faith Assessment into Nurse Practitioner Education \& Practice. The Journal of Christian Nursing. 2014; 31(4): 258-262. http: //dx.doi.org/10.1097/CNJ.0000000000000099

[18] Otto, A. Cura personalis. Dot Magis, the blog of Ignatianspirituality.com. 2013; Available from: http://www.ignatianspiritua lity.com/16996/cura-personalis/ 